\title{
Study of the Aero-Acoustic and Aerodynamic Effects of Soft Coating upon Airfoil*
}

\author{
János VAD**, Gábor KOSCSÓ ${ }^{* *}$, Miklós GUTERMUTH*, \\ Zsolt KASZA**, Tamás TÁBI** and Tibor CSÖRGÖ***
}

\begin{abstract}
Comparative acoustic and wind tunnel experiments were carried out on uncoated and coated isolated airfoils. The aim of the tests was to survey the airfoil noise reducing effect and the aerodynamic impact of the acoustically soft coating consisting of filaments, as a preliminary study in application of such coatings to axial flow turbomachinery bladings. It was found in the acoustic tests that the coating successfully reduces the sound pressure in the frequency range critical from the aspect of human audition. The wind tunnel experiments included laser Doppler anemometer studies on the development of the boundary layers and on the wake structure, and static pressure measurements on the blade surface and in the wake. The coating reduced the lift and increased the drag. A proposal has been made for further studies in order to retain the advantageous acoustic effects of the coating while avoiding the undesirable aerodynamic impact.
\end{abstract}

Key Words: Axial Flow Turbomachinery, Fan Noise, Airfoil Aerodynamics, Wind Tunnel Tests, LDA Measurements, Flow Generated Noise

\section{Introduction}

The reduction of aerodynamic noise of axial flow fans has been the subject of extensive research activity in the past decades. Realization of the required performance with rotors of reduced circumferential speed, diameter, and losses, i.e. development of methods to design highly efficient fans of high specific performance ${ }^{(1)}$ is a basic means of reducing turbofan noise. The rotor noise can be suppressed e.g. by reducing the relative tip clearance ${ }^{(2)}$, but this may lead to problems in practical applications. Successful reduction of tip clearance-flow generated noise and interaction noise can be carried out e.g. by means of non-radial blade stacking, i.e. sweep ${ }^{(3)}$ and skew ${ }^{(4)}$. The noise generated by the inlet turbulence on the blades can be moderated by reducing the turbulence-generating effects upstream of the rotor. The blade boundary layer (BL) noise and the wake noise are usually diminished if

* Received 17th January, 2006 (No. 05-5142)

** Department of Fluid Mechanics, Budapest University of Technology and Economics, Bertalan Lajos u. 4-6, H1111 Budapest, Hungary. E-mail: vad@ara.bme.hu

*** Department of General Zoology, Eötvös Loránd University, Pázmány Péter sétány 1/C, H-1117 Budapest, Hungary the aerodynamic losses of the blade are minimized ${ }^{(5)}$, for example, with use of controlled diffusion profiles ${ }^{(6)}$.

The above solutions mostly influence the construction and geometry of the machinery. Beside these efforts, other ways are being sought for the production of silent fans. One solution could be the appropriate formation of blade surface roughness elements or special blade surface structures. It is known that the surface treatment has an impact on the aerodynamic characteristics. However, the impact of such a treatment on the noise of airfoils or of axial fan blades has been less investigated.

The blades of an axial flow fan operate in cascade (blade row) arrangement. However, if the solidity (blade chord-to-spacing ratio) of an axial flow blade row is relatively low - as in the case of several industrial fans ${ }^{(7)}$ the operation of a blade section is considered to be analogous to that of an isolated airfoil ${ }^{(4)}$. This gives the idea to search for cases in the animal world in which airfoil-like aerodynamic growths such as bird wings operate silently due to their special surface characteristics; and to attempt adopting such characteristics to turbomachinery blades for noise reduction.

Figure 1 shows the enlarged photographs of owl wing surface sections and feathers. As the figure illustrates, owls ${ }^{(8)}$ have small feathers equipped with filaments near 

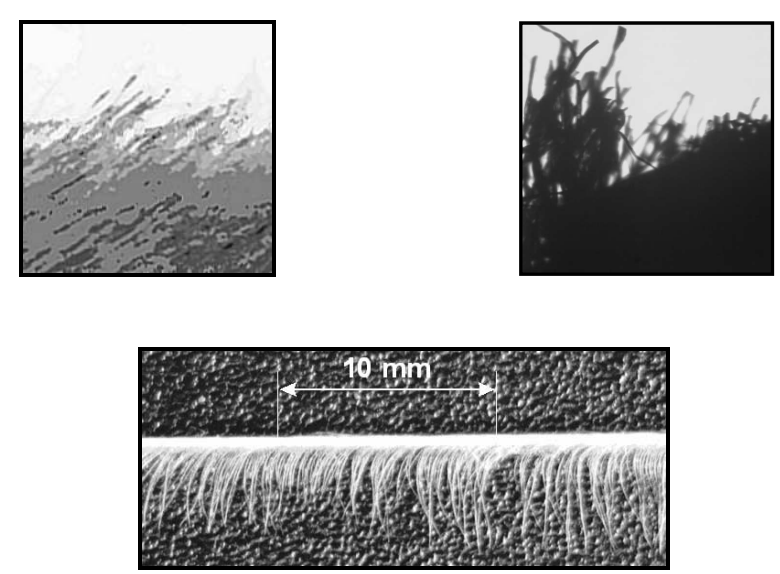

Fig. 1 Above: photographs of fuzzy surface of the front part of owl wing (left) and surface of velvet (right) taken with identical enlargement; below: photo of owl feather with filaments

the leading edge (LE) of their wing, providing a velvetlike "coating". This feature is acknowledged by ornithologists as a specialty among night hunting birds. In ornithology, it is considered as a triviality that the special structure of owl feathers contributes to very silent wing operation $^{(9),(10)}$. This gave the idea of carrying out the studies presented in this paper. The investigations reported herein were carried out at the Department of Fluid Mechanics (DFM), Budapest University of Technology and Economics. Garment trade velvet was chosen in order to form an acoustically soft coating on an airfoil of case study. As Fig. 1 also suggests, the velvet consists of filaments similar to the fibrous front feather elements of owls. The velvet filaments and the feather elements have characteristic length and number per unit area in the same order of magnitude ( $2 \mathrm{~mm}$ length, 100 pieces $/ \mathrm{mm}^{2}$ density). Therefore, the authors judged this type of velvet appropriate for coating tests as a first approach, although a difference appears in the filament structures. In future tests, electrostatically produced velvet of unidirectional filaments could be used, and finally, the aid of material technology will be needed in order to convert the research results to axial fan applications.

The case study airfoil, without and with such coating, has been experimentally investigated in order to judge the acoustic and aerodynamic effects of the surface treatment.

It must be noted here that development of selfsticking coatings could provide e.g. a simple subsequent means for noise reduction on existing fans.

\section{Nomenclature}

$$
\begin{aligned}
& c_{p}: \text { static pressure coefficient (Eq. (1)) } \\
& c_{D}: \text { drag coefficient (Eq. (3)) } \\
& c_{L}: \text { lift coefficient (Eq. (3)) } \\
& D: \text { distance from the wall normalized by the chord } \\
& d F: \text { elemental force acting on the airfoil section }
\end{aligned}
$$

$h:$ airfoil chord

$L$ : sound pressure level

$L_{A}:$ A-weighted sound pressure level

$\Delta L$ : difference between sound pressure levels with and without coating

$p:$ static pressure

$d s$ : elemental section of span

$T u$ : turbulence intensity (Eq. (2))

$v$ : velocity

$Y:$ vertical coordinate normalized by the chord

$\rho$ : fluid density

\section{List of Abbreviations}

BL : boundary layer on the airfoil

LDA : laser Doppler anemometry

LE : airfoil leading edge

PS : airfoil pressure side

SS : airfoil suction side

TE : airfoil trailing edge

2D : two-dimensional (flow)

\section{Subscripts}

$\mathrm{b}:$ at the boundary of the LDA-measured profiles in : at the inlet plane

\section{Airfoil of Case Study}

The rectilinear, isolated airfoil of case study, modeling an axial fan blade at the present state of research, is of RAF-6E profile, with known lift and drag characteristics measured in two-dimensional (2D) tests ${ }^{(11)}$. This profile is a representative one for the present study since it has been used in classic axial fan design. It is also relatively easy to manufacture, given that the pressure surface is plane. The chord length of the airfoil is $h=200 \mathrm{~mm}$, considered as the length of the pressure surface, together with the radii of fillets at the LE and the trailing edge (TE). The span is $490 \mathrm{~mm}$. These basic geometrical data are anyway in harmony with the geometry of a stock owl (Bubo Bubo) wing (mean chord is approx. $0.2 \mathrm{~m}$, mean span of wing is $\left.0.46 \mathrm{~m}^{(9)}\right)$. At the inlet air velocity and air temperature valid for the wind tunnel studies presented herein, considering a maximum lift coefficient of $1.3^{(11)}$, the model airfoil performs a lift force of approx. $10 \mathrm{~N}$, which is anyway the half of the mean weight of a stock owl ${ }^{(9)}$.

The model airfoil has been manufactured from a plastic material by means of computer-controlled milling. A plate representing a part of the pressure surface is detachable, and a pit has been milled inside of the airfoil for the implementation of static pressure taps of $1 \mathrm{~mm}$ internal diameter at midspan. The airfoil was equipped with appropriate mounts, making its inclusion possible in acoustic and wind tunnel studies with minimum flow disturbance and with the possibility for incidence angle adjustment. In acoustic studies, a 1:2 scaled-down model airfoil was used in order to accommodate to the geometrical conditions of the acoustic experimental facility. The order of magnitude 


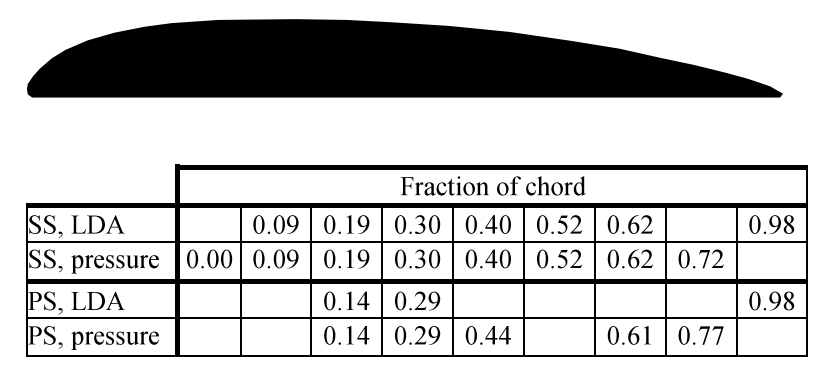

Fig. 2 The airfoil profile, with midspan measurement locations

of geometrical data — chord length and span - of the airfoils under acoustic as well as aerodynamic investigations is typical for middle-scale industrial axial fan blades ${ }^{(7)}$.

Oil flow visualization tests in the wind tunnel, not presented here, pointed out that at midspan, the flow can be considered as 2D and thus, Ref. (11) can be taken as a basis for judgment of the aerodynamics of the midspan section. Based on Ref. (11), incidence angles of the uncoated profile of $5 \mathrm{deg}$ and $15 \mathrm{deg}$ were selected for detailed fluid dynamical studies. These incidence angles result in approximately the highest lift-to-drag ratio and highest lift, respectively, corresponding to the best efficiency and total pressure peak points of an axial flow turbomachine ${ }^{(12)}$. The incidence angle is taken as the angle between the pressure surface and the direction of the wind tunnel axis. Figure 2 shows the airfoil profile, with the locations of the surface static pressure and BL laser Doppler anemometer (LDA) velocity measurements presented herein. In Fig. 2, the fraction of chord means the chordwise distance of the measurement location from the LE normalized by the chord length, and the airfoil suction and pressure sides are abbreviated as SS and PS, respectively.

The flow field was also investigated in an inlet plane 0.5 chords upstream of the LE by means of LDA. The inlet velocity field was found here uniform and axial, represented by the velocity $v_{i n}$. The inlet turbulence intensity (see Eq. (2) later) was 0.5 percent for both the acoustic and wind tunnel tests, approximated on the basis of LDA measurements. The Reynolds number, based on the chord, inlet velocity at midspan $v_{\text {in }}$, and kinematical viscosity of air at $20^{\circ} \mathrm{C}$ was 145500 . This Reynolds number value, being representative for the blades of low-speed ventilating fans ${ }^{(7)}$, has been set for both the acoustic and wind tunnel studies. The Mach number computed with $v_{\text {in }}$ for the acoustic test and speed of sound in air at $20^{\circ} \mathrm{C}$ was 0.06 . Therefore, the flow was considered truly incompressible. The noise reduction studies presented in the paper and planned in the future are valid for Mach numbers characterizing low-speed industrial axial fans, i.e. in the order of magnitude not higher than 0.1. Higher Mach numbers, i.e. higher flow velocities would probably result in serious constructional difficulties in realization of
Table 1 Uncertainty of presented quantities

\begin{tabular}{|l|l|}
\hline \multicolumn{1}{|c|}{ Quantity } & \multicolumn{1}{c|}{ Absolute uncertainty } \\
\hline \hline$L, 31.5$ to $125 \mathrm{~Hz}$ & $\pm 0.7 \mathrm{~d} B$ \\
\hline$L, 160$ to $400 \mathrm{~Hz}$ & $\pm 0.5 \mathrm{~d} B$ \\
\hline$L, 400$ to $4000 \mathrm{~Hz}$ & $\pm 0.2 \mathrm{~d} B$ \\
\hline$c_{p}$ & \pm 0.03 \\
\hline$v / v_{\text {in }}$ & \pm 0.02 \\
\hline
\end{tabular}

noise-reducing coatings (deformation or even removal of the coating layer).

During the tests, the entire surface of the airfoil was coated. The velvet layer caused an increase of approx. 10 percent in airfoil thickness at the thickest profile section.

Table 1 indicates the absolute uncertainty of the quantities presented in the paper, estimated on the basis of the experimental uncertainties of related measurement data.

\section{Acoustic Studies}

The following facility at DFM, shown schematically in Fig. 3, was used for investigation of the airfoil noise. A low-speed radial fan of minimized noise emission provides airflow to a confuser, equipped with an absorber type silencer. This confuser is connected to a pipeline, followed by a second absorber type silencer. Downstream of this silencer, a second, aerodynamically optimized outlet confuser is located, equipped with noise absorbing layer on the inner wall, producing a silent free jet into a reverberation room of $8.8 \mathrm{~m} \times 5.9 \mathrm{~m} \times 4.2 \mathrm{~m}$. The exit cross-section of the outlet confuser is $0.150 \mathrm{~m}$ (height) $\times$ $0.350 \mathrm{~m}$ (width). The midspan airfoil section, with horizontal span, is exposed to this free jet. The air exits from the reverberation room through a silencer preventing the ambient noise from entering the room. This arrangement resulted in a low background and free jet noise, which was considerably lower than the evaluated additional noise generated by the airfoil.

The spectral distribution of the sound pressure level was measured with the use of a $1 / 2$ inch Brüel \& Kjaer (B\&K) Type 4134 condenser microphone with B\&K Type 2639 preamplifier, B\&K Type 2807 two-channel microphone drive unit, connected to a PONT PSA-100 FFT analyzer. The microphone was calibrated by means of a VEB RFT-MESSELEKTRONIK 00003 pistonphone microphone calibrator. The scope of the investigation was to determine the relative sound pressure levels of the uncoated and coated configurations. The sound pressures of noise of both the uncoated and coated airfoils were measured for incidences of 0,5 and $15 \mathrm{deg}$. The sound pressure was measured at different locations in the vicinity of the airfoil. In a particular experimental case, no significant variance was experienced in the measured overall sound pressure level for the various microphone locations. In each microphone arrangement, briefly the same trends were observed in modification of sound pressure levels, 


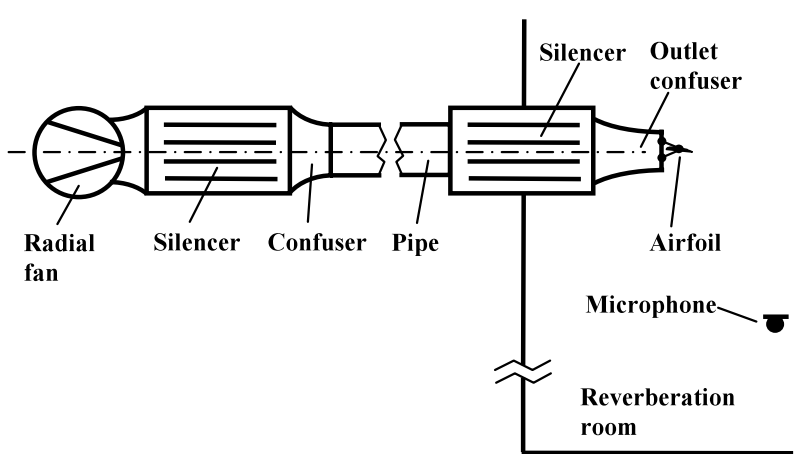

Fig. 3 Experimental setup for acoustic studies

Table 2 A-weighted sound pressure levels

\begin{tabular}{|l|c|}
\hline Test case & $\boldsymbol{L}_{\mathbf{A}}[\mathbf{d} \boldsymbol{B}(\mathbf{A})]$ \\
\hline Airfoil uncoated, 0 deg inc. & 64.4 \\
\hline Airfoil coated, 0 deg inc. & 63.0 \\
\hline Airfoil uncoated, 5 deg inc. & 63.0 \\
\hline Airfoil coated, 5 deg inc. & 62.7 \\
\hline Airfoil uncoated, 15 deg inc. & 74.7 \\
\hline Airfoil coated, 15 deg inc. & 73.8 \\
\hline
\end{tabular}

due to coating and due to changing incidence. Therefore, only a representative arrangement is discussed further on, in which the microphone was placed 3 chords downstream of the TE and 6 chords below it (but at $1.5 \mathrm{~m}$ from the floor), with the microphone axis aligned parallel to the incident flow. The future aim of the research presented in the paper is industrial noise control. For this reason, the A-weighted (overall) sound pressure level, being representative from the viewpoint of human audition, has been obtained in evaluation of the measurement results. Table 2 presents the A-weighted sound pressure levels for the various test cases. The data show that the coating caused slight overall noise reduction for each incidence. Such reduction of A-weighted sound pressure level was indicated by the measurements repeatably at each incidence under investigation. It must be acknowledged that the noise reducing effect is weak and is not sufficient from practical noise control point of view; however, these results are still promising at the present preliminary state of research. The validity of the particular quantitative results is confined to the measurement circumstances reported herein; however, one of the preliminary aims of the present work was to point out qualitatively the potential effect of noise reduction due to soft coating. Since no tonal noise component has been detected during the measurements, the one-third octave band representation of the measured sound pressure spectra was considered adequate from the viewpoint of resolution. Figure 4 shows the measured one-third octave band sound pressure spectra. During the measurements of the jet without airfoil, the airfoil mount has been left in the jet, i.e. solely the airfoil has been removed. As the figure suggests, the airfoil has the greatest acoustic effect in the frequency range starting with $100 \mathrm{~Hz}$ and ex-
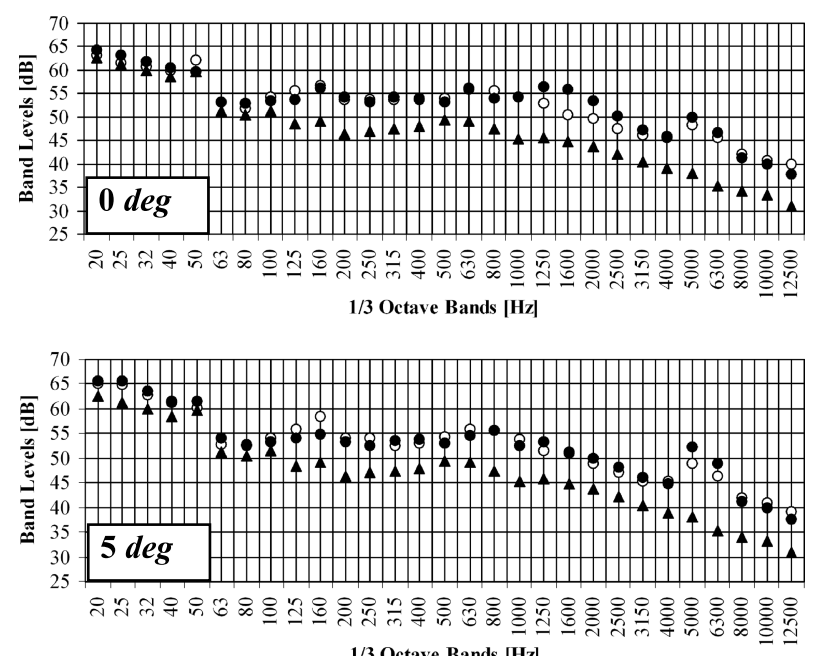

1/3 Octave Bands [Hz]

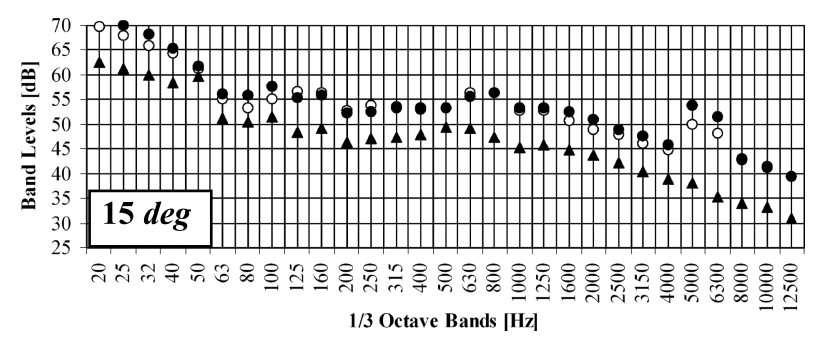

Fig. 4 Sound pressure spectra with measured $L$. Black dots: uncoated, white dots: coated airfoil, black triangles: jet without airfoil
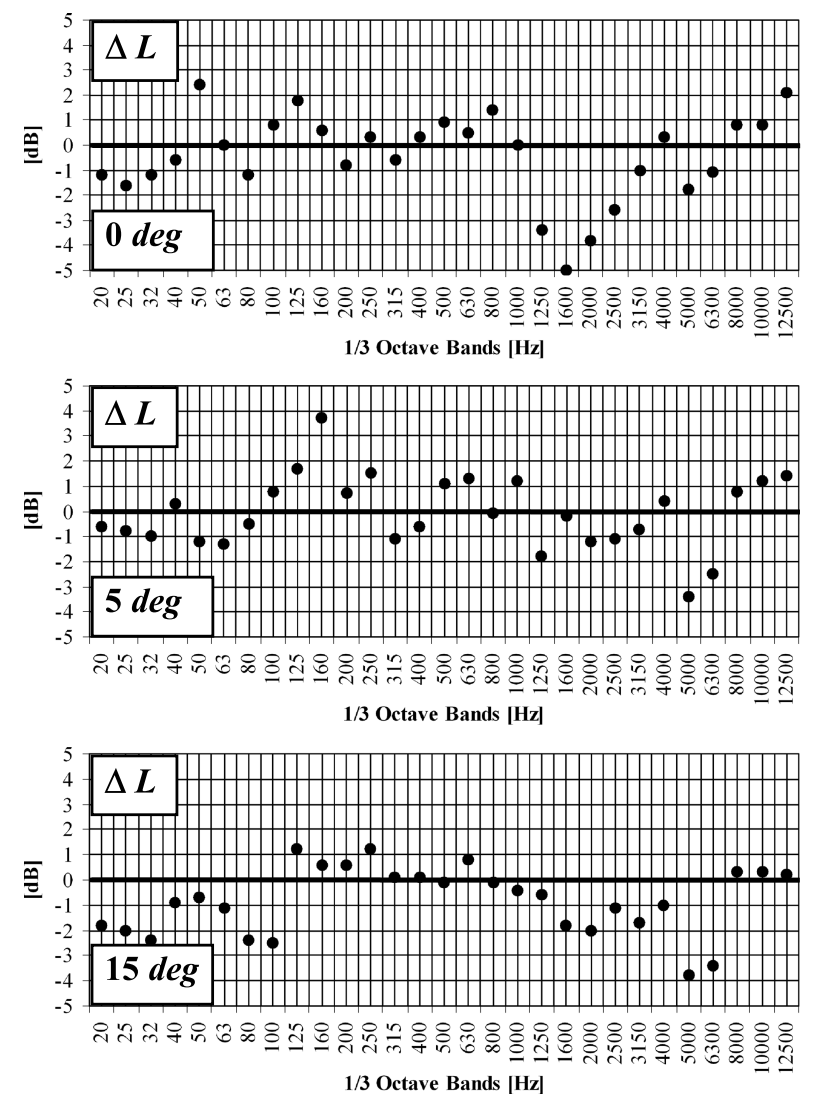

Fig. 5 Spectral distribution of the difference of sound pressure levels measured for the coated and uncoated airfoils 
tending over $10000 \mathrm{~Hz}$. Figure 5 presents the difference between the sound pressure levels of the coated and uncoated airfoils, i.e. negative values correspond to noise reduction due to coating. This evaluation is consequent with the measurement methodology in which levels have been established. Although the coating increased the noise in an intermediate range, it has a noise reducing effect at frequencies lower than $80 \mathrm{~Hz}$, and in the frequency domain between 1000 and $6300 \mathrm{~Hz}$ (negative $\Delta L$ values). The sound pressure level has been increased in the frequency range beyond $8000 \mathrm{~Hz}$ (positive $\Delta L$ values). However, this frequency domain is beyond the most sensitive range from the viewpoint of human audition. Noise reduction in the 1000 to $5000 \mathrm{~Hz}$ frequency range is an effective means for moderation of A-weighted sound pressure level. Moderate noise emission in this range gives a potential for improvement of the human audibility in the vicinity of the noise source.

In the following, it shall be investigated how the coating, proven to be beneficial from a noise emission point of view, influences the aerodynamic behavior of the airfoil.

\section{Wind Tunnel Experiments}

The wind tunnel studies were carried out in the National Physics Laboratory (NPL) type horizontal wind tunnel $^{(13)}$ at DFM. The sketch of the experimental setup is presented in Fig. 6. An inlet confuser with honeycombs as well as static pressure taps for flow rate measurements, followed by a straight duct, precedes the test section. Turbulence generator grids can be inserted downstream of the confuser for setting various turbulence levels in the air entering the test section. The test section of rectangular cross-section with $430 \mathrm{~mm}$ height and $520 \mathrm{~mm}$ width is equipped with glass endwalls for optical access during LDA measurements. The airflow is induced by an axial fan of variable speed far downstream of the test section. An ILA flowPOINT fp50-fus LDA system has been installed into the test section. The diameter and the length of the LDA probe volume are 0.3 and $3.3 \mathrm{~mm}$, respectively. The flow was seeded with oil droplets of mean diameter $1.5 \mu \mathrm{m}$ by means of a DANTEC Fog 2005 Loop seeding generator.

The airfoil was located at the mid-height of the test section, with horizontal span, and chord parallel to the tunnel axis at zero incidence. LDA measurements were carried out at the locations indicated in Fig. 2 at midspan of the airfoil. Five hundred data readings were collected for each measuring point. During the BL studies, the data was collected along lines normal to the blade surface. The velocity component which is parallel to the tunnel axis and is tangential to the blade surface was measured. The measurement grid was of the highest resolution closest to the blade surface and was coarsened farther from the surface, maintaining a mean expansion ratio of approx. 1.2.

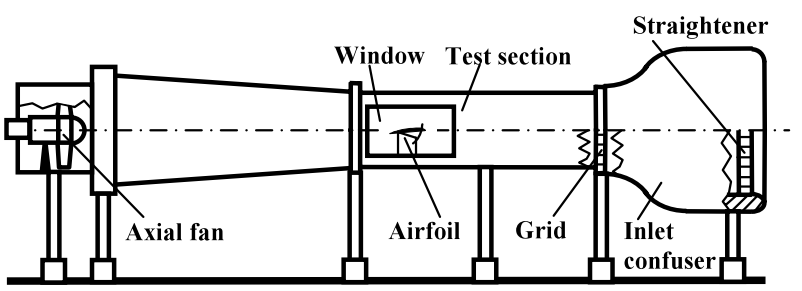

Fig. 6 Experimental setup for aerodynamic studies
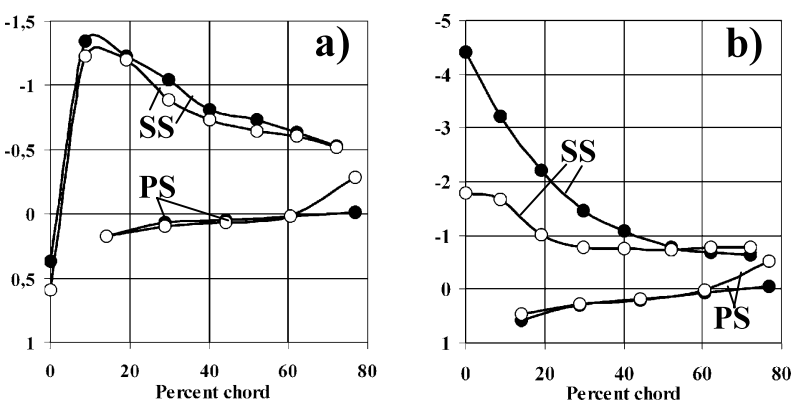

Fig. 7 Surface static pressure coefficient: $c_{p}$. a) $5 \mathrm{deg}$ incidence, b) 15 deg incidence. Black dots: uncoated, white dots: coated airfoil

The static pressure data (of both blade surface and wake), with reference to the static pressure at the inlet plane, has been measured by means of a Betz micromanometer at midspan. The static pressure in the wake was measured with the use of a small-scale static pressure probe.

Figure 7 shows the comparative static pressure coefficient diagrams for the surface of uncoated and coated airfoils at $5 \mathrm{deg}$ and $15 \mathrm{deg}$ incidence (Note that the vertical scales are different). The static pressure coefficient has been defined as

$$
c_{p}=\frac{p-p_{\text {in }}}{(\rho / 2) v_{\text {in }}^{2}}
$$

The lack of data closer to the TE is due to the absence of pressure taps on the thinnest section of the airfoil. The data point sets predominantly in the negative and positive $c_{p}$ range represent depression and overpressure, i.e. SS and PS data, respectively (SS and PS data are marked in Fig. 7, and later, in Fig. 8). The figures indicate that, except for the reduction of overpressure near the TE, the coating has minor influence on the static pressure development on the PS at both incidences. Nevertheless, the SS depression has been reduced due to coating even at $5 \mathrm{deg}$ incidence. Such a decrease is even more obvious at $15 \mathrm{deg}$ incidence, for which the nearly constant $c_{p}$ data starting at 30 percent chord suggests the presence of a flow separation zone on the coated airfoil.

The effects of coating were further investigated on the basis of the comparison of the LDA-measured velocities $v_{\mathrm{b}}$ at the boundary of the LDA velocity profile measurements (at 34 percent chord away from the blade surface, along lines normal to it, see later Figs. 10 to 12). Such data, nor- 

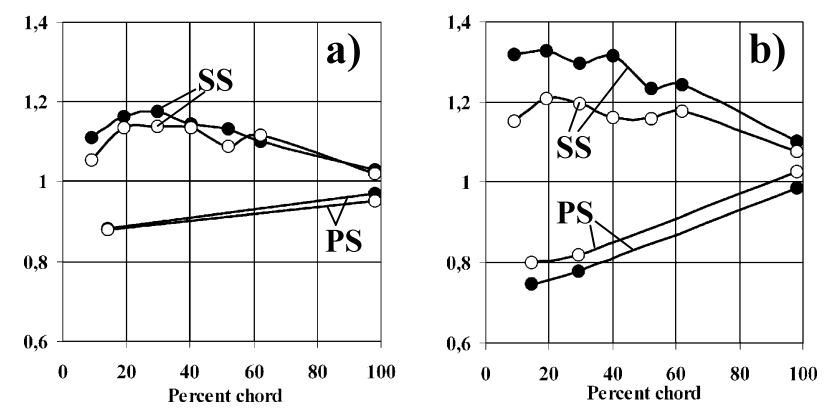

Fig. 8 Velocity at the boundary of LDA-measured domains: $v_{\mathrm{b}} / v_{\text {in }}$. a) $5 \mathrm{deg}$ incidence, b) $15 \mathrm{deg}$ incidence. Black dots: uncoated, white dots: coated airfoil
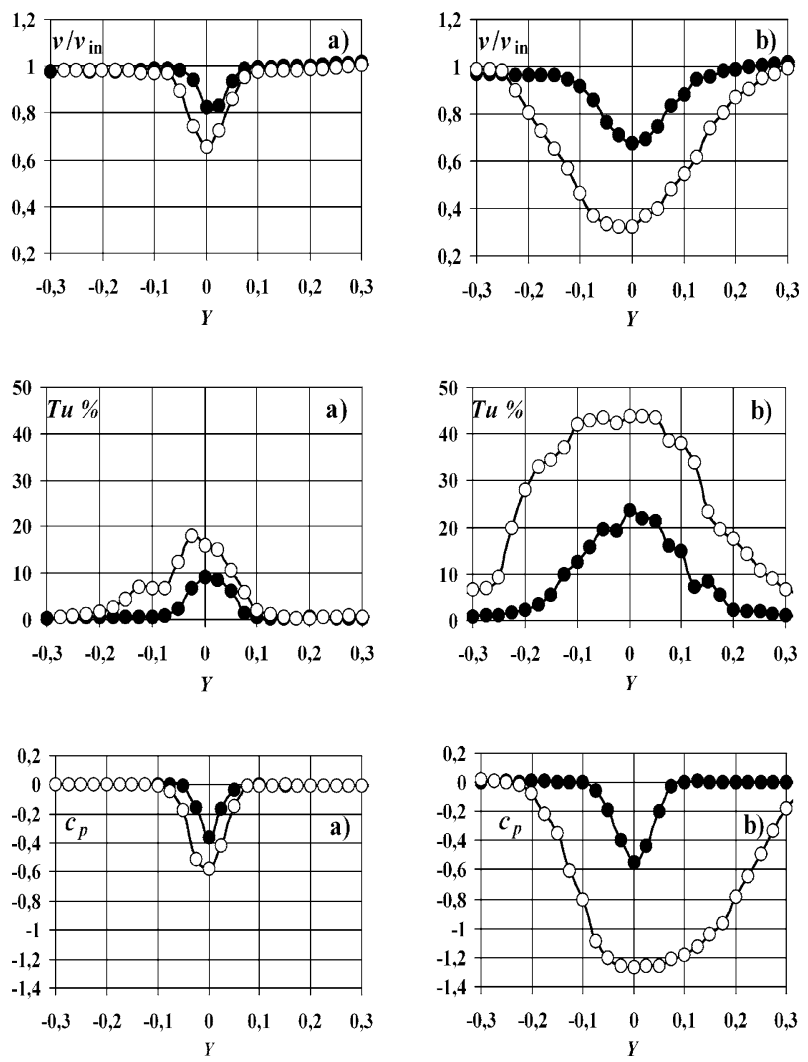

Fig. 9 Wake studies 50 percent chord downstream of TE. a) 5 deg incidence, b) 15 deg incidence. Black dots: uncoated, white dots: coated airfoil

malized by $v_{\text {in }}$, are shown in Fig. 8 . The lack of LDA data in the intermediate zone of PS is due to the airfoil mounting device acting as an optical obstacle. The data point sets predominantly in the range above and below unity represent accelerated and decelerated regions compared to the inlet flow, i.e. SS and PS data, respectively. On the SS, the coating appears to increase the wall friction, thus moderating the acceleration and the related depression. Such effect is especially strong at $15 \mathrm{deg}$ incidence, at which the coating also appears to obstruct the pressure surface contour of the airfoil in flow deceleration.

The next step was the analysis of the airfoil wake structure. Figure 9 shows the LDA-measured velocity and
Table 3 Lift and drag coefficients

\begin{tabular}{|l|c|c|}
\hline Test case & $c_{\mathbf{L}}$ & $c_{\mathbf{D}}$ \\
\hline \hline 5 deg incidence, data from [11] & 0.90 & 0.02 \\
\hline 5 deg incidence, uncoated & 0.75 & 0.03 \\
\hline 5 deg incidence, coated & 0.65 & 0.08 \\
\hline 15 deg incidence, data from [11] & 1.30 & 0.13 \\
\hline 15 deg incidence, uncoated & 1.45 & 0.12 \\
\hline 15 deg incidence, coated & 0.85 & 0.61 \\
\hline
\end{tabular}

turbulence intensity distribution as well as the static pressure profile in the wake, in a plane 50 percent chord downstream of the TE and normal to the axial direction. The vertical coordinate is normalized by the chord, thus giving a dimensionless vertical coordinate $Y$. The measured profiles are arranged in such a way that negative and positive $Y$ values represent approximately the PS and SS parts of the wake, respectively. The turbulence intensity is defined as

$$
T u \%=\frac{\sqrt{\overline{(v-\bar{v})^{2}}}}{|\bar{v}|} \cdot 100
$$

where $\bar{v}$ is the mean velocity computed from the LDA data obtained in a given point, and $\sqrt{\overline{(v-\bar{v})^{2}}}$ is the root mean square value of $(v-\bar{v})$ data computed for the individual LDA-measured $v$ results.

Figure 9 indicates that the coating causes considerably reduced velocity, increased turbulence level, and reduced static pressure already at $5 \mathrm{deg}$ incidence. Such effects are further magnified at $15 \mathrm{deg}$ incidence. It is obvious that the coating causes not only the reduction of lift but also the increase of drag via increased total pressure losses in the wake. It appears to hasten the SS BL separation at higher incidences at which the uncoated airfoil is still able to operate in a reliable manner.

In order to quantify briefly the effects discussed above, the lift coefficients were estimated by means of approximate numerical integration of measured static pressures (Fig. 7) over the airfoil surfaces, and considering the resultant force component normal to the inlet flow. The drag coefficients have also been estimated on the basis of the measured flow characteristics at the inlet plane $(0.5$ chord upstream of the LE) and at the outlet plane (Fig. 9), taking the skin friction on the tunnel walls into consideration, and using the integral momentum equation. Table 3 presents the results, compared to the data in Ref. (11) with the lowest available Reynolds number of 300000 . The lift and drag coefficients are defined as

$$
c_{\mathrm{L}, \mathrm{D}}=\frac{d F_{\mathrm{L}, \mathrm{D}}}{d s h(\rho / 2) v_{\text {in }}^{2}}
$$

where $\mathrm{L}$ and $\mathrm{D}$ represent lift and drag, respectively.

Although the Reynolds numbers valid for the present experiments and for the data in Table 3 taken from Ref. (11) are different -145500 and 300000 , respectively —, the comparability of the experiment- and 

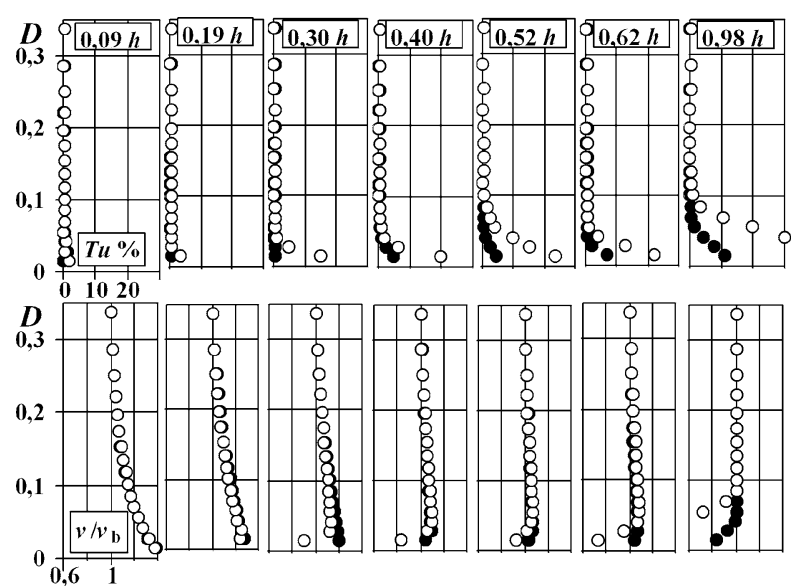

Fig. 10 Development of SS BL at 5 deg incidence. Black dots: uncoated, white dots: coated airfoil

literature-based lift and drag coefficients is supported by the following comments. As recommended in Ref. (4), the Reynolds number for an axial flow fan blade should exceed approximately 150000 in order to obtain reasonably good fan efficiency. Above this threshold, only moderate efficiency improvement is expected. Since the fan efficiency is closely related to the lift and drag of the blade sections ${ }^{(14)}$, the above yield that only minor changes are expected in $c_{\mathrm{L}}$ and $c_{\mathrm{D}}$ of a blade section - or of an airfoil being in aerodynamic analogy with the blade section - above Reynolds number $\approx 150000$. Indeed, as the data in Ref. (11) show, increase of the Reynolds number of 300000 by the multiplying factor of 2 causes not more than $4 \%$ and $12 \%$ change in $c_{\mathrm{L}}$ and $c_{\mathrm{D}}$, respectively, regarding the incidences discussed herein. Therefore, authors felt reasonable to consider the data from literature $^{(11)}$ in Table 3 as a basis for brief comparison with the experiment-based results.

Taking the difference in the Reynolds numbers, the rough approximations in numerical integration, and further approximations (e.g. viewing the present airfoil as a 2D one) into consideration, it can be stated that the lift and drag coefficients computed for the uncoated case study airfoil are in fair agreement with the data from the literature. This confirms the adequateness of the experiments reported herein. It is clear that the coating causes unacceptable reductions in lift and increases in drag, i.e. drastic reductions also in the lift-to-drag ratio. Such deterioration is enormous at $15 \mathrm{deg}$ incidence.

The development of the BL along the chord has been mapped via LDA measurements. Figures 10 and 11 present the measured SS velocity profiles normalized by the actual $v_{b}$ values, and the turbulence intensity profiles, for the two incidences. Only segments of the BL profiles could be presented (also in Fig. 12), due to the limited available space in the paper. Extended data sets are available at DFM. The presented quantities and the
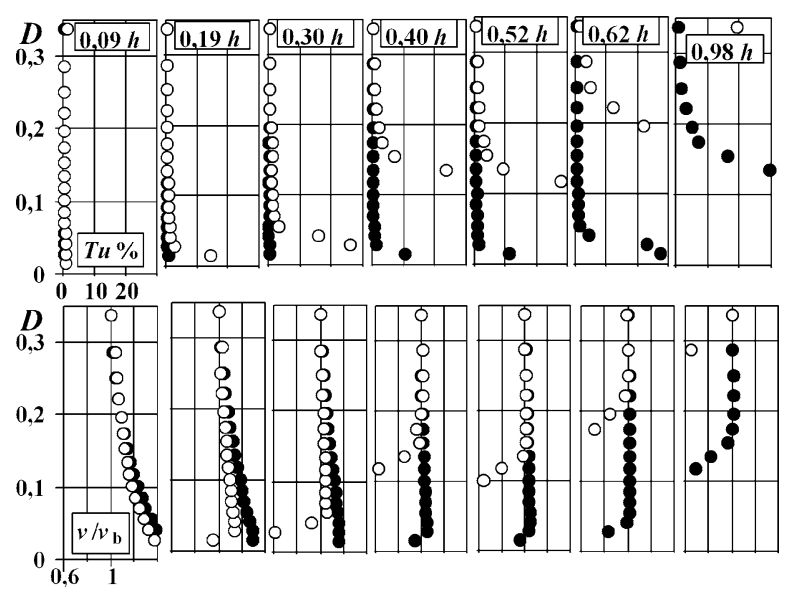

Fig. 11 Development of SS BL at 15 deg incidence. Black dots: uncoated, white dots: coated airfoil

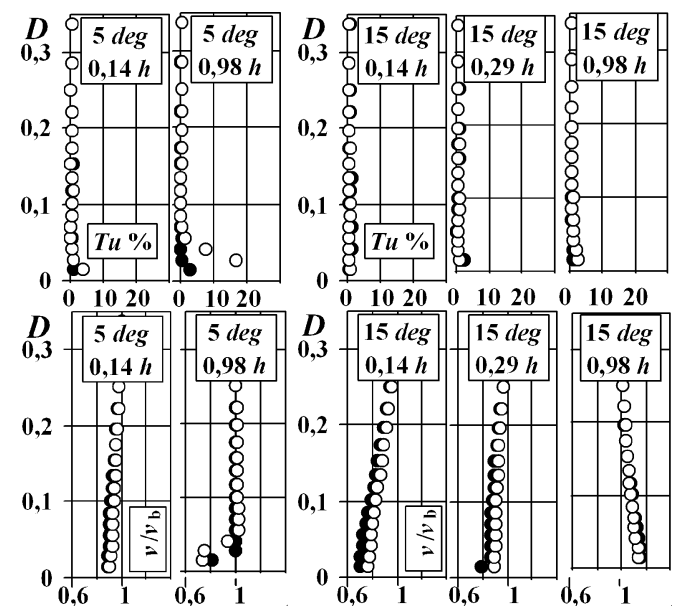

Fig. 12 Characteristics of PS BL. Black dots: uncoated, white dots: coated airfoil

scaling are specified in the first diagram of each row. The distance from the wall is normalized by the chord $h$, thus giving a dimensionless distance $D$. At presence of coating, $D$ is measured from the modified surface. The point measured farthest from the surface is at $D=0.34$, and is characterized by $v_{\mathrm{b}}$ (conf. Fig. 8).

At 5 deg incidence, the coating hastens the thickening of the SS BL otherwise developing regularly, via increased wall friction. It also causes drastically increased turbulence intensity near the wall. Such effects are even more pronounced at $15 \mathrm{deg}$ incidence, at which the coating causes the separation of the SS BL. Despite the high airfoil loading, the SS BL is naturally thickened but still remains attached without coating over the dominant portion of chord.

Figure 12 presents the LDA-measured characteristics of the PS BL at different incidences and positions. As the figure suggests, the coating causes BL thickening and turbulence intensification also on the PS at 5 deg incidence, especially near the TE. However, these effects are much weaker than those which can be observed on the SS. At 
15 deg incidence, it is especially conspicuous that the coating obstructs the pressure surface contour of the airfoil in flow deceleration - and thus, it inhibits the development of overpressure - near the LE, i.e. the velocity near the surface is lower without than with coating (conf. Fig. 8).

\section{Combination of Acoustic and Aerodynamic As- pects: Further Research Steps}

The coating under present investigation widened the wake and increased the turbulence level over the entire blade surface and in the wake. In a classic sense, one may expect that such effects would increase the BL noise and the wake noise. However, the acoustic studies suggested just the opposite tendency. The noise reduction can be explained on the basis of the following assumptions, necessitating further research steps:

1) The noise generated by the inlet turbulence may have possibly been reduced by the application of acoustically soft coating near the LE of the airfoil. This is in accordance with the fact that owls have velvet-like feathers only near the LE of their wing. If the entire wing were covered by such feathers, the owl could quite possibly operate only with reduced performance and increased losses. Birds live in the near-ground region of the atmosphere. The lowest $100 \mathrm{~m}$ layer is characterized by a mean velocity in the order of magnitude of some $\mathrm{m} / \mathrm{s}$, and with a turbulence intensity which might even be exceeding 20 percent $^{(15),(16)}$. In natural environments with vegetation, turbulent vortices in the order of magnitude smaller than the size of an owl wing are characteristic. Therefore, the inlet turbulence may be a significant cause of noise.

2 ) The noise caused by turbulent fluctuations in the BL may have been reduced. Although the coating increased the turbulence intensity in the BL, its noisereducing function dominated over the noise-generation effect of increased turbulence. This feature of the coating is to be examined at different turbulence levels. The power spectra of turbulence may play an important role in this noise reduction mechanism. Therefore, detailed turbulence measurements, by means of hot-wire anemometry, over the airfoil surface and in the wake are to be carried out.

3 ) Although the turbulence intensity level in the wake was increased due to the coating, its spectral distribution may have been modified in such a way that the related wake noise, in terms of the A-weighted sound pressure level, has been reduced. Figure 5 suggests that the reduction of sound pressure at higher frequencies is at the cost of increase of noise at middle frequencies. This assumption also necessitates hot-wire anemometer measurements over the blade surface and in the wake, in order to examine the correlation between sound pressure and turbulence spectra. Computational aero-acoustics with involvement of Large Eddy Simulation ${ }^{(17)}$ also support such investigations.

The further research plan involves the following aspects.

1) The acoustically soft fibrous coating is to be covered by plastic foil of thickness in the order of magnitude of $0.01 \mathrm{~mm}$. Such "cover" provides aerodynamically beneficial smooth airfoil surface, thus eliminating the aerodynamic demerits reported herein. In addition, it is acoustically transparent and thus, it enables retaining the noise reducing effect of the fibrous coating.

2 ) In order to distinguish between the major effects of inlet turbulence as well as turbulent fluctuations in the BL from the viewpoint of noise generation and suppression, the fibrous coating equipped with the above mentioned plastic cover is to be restricted to the following zones of the airfoil surface, in consecutive research steps: i) the near-LE region, ii) accelerating flow region on the $\mathrm{SS}$, iii) decelerating flow region on the SS, iv) the PS, v) combinations of the above.

3 ) Airfoils of porous or/and visco-elastic materials are also to be tested.

4 ) The tests are to be carried out with various coating types and inlet turbulence levels.

\section{Summary}

An experimental investigation was carried out on an isolated rectilinear airfoil in order to survey the acoustic and aerodynamic effects of an acoustically soft coating consisting of filaments (velvet), covering the entire airfoil surface, at incidences of $0 \mathrm{deg}$, of maximum lift-to-drag ratio and of maximum lift of the uncoated airfoil. The results are summarized as follows:

1) The coating was found to reduce the A-weighted sound pressure level of noise generated by the airfoil at each incidence. The coating reduced the sound pressure level in the frequency range critical from the viewpoint of human audition, and increased it at lower and higher frequencies less significant from the aspect of A-weighting.

2 ) The coating increased the wall friction. This resulted in unfavorable aerodynamic effects, manifesting themselves for the most part on the suction side. The acceleration and the related depression have been moderated on the suction surface. The suction side boundary layer and consequently, the wake, have been thickened. The turbulence has been intensified in the boundary layer and in the wake. Such phenomena were more pronounced at high incidence, at which the coating caused even the separation of the suction side boundary layer, remaining still attached without coating. These effects led to unacceptably strong reduction in lift and increase in drag, being very drastic at high incidence.

3 ) To retain the beneficial acoustic effects but to avoid the unfavorable aerodynamic impact, further studies are necessary. This should involve coating combined with 
acoustically transparent plastic foil layer, various coating materials and configurations restricted to only a part of the airfoil surface, and various inlet turbulence levels. Airfoils of porous or/and visco-elastic materials are also to be tested.

4 ) For a better understanding of noise reduction mechanisms due to coating, the former experiments shall be supplemented with turbulence spectra measurements over the blade surface and in the wake.

\section{Acknowledgment}

This work has been supported by the Hungarian National Fund for Science and Research under contracts No. OTKA T 043493, K63704 and T 037651, and, on the behalf of J. Vad, out of the István Széchenyi Fellowship under contract No. SZÖ 271/2003.

\section{References}

( 1 ) Vad, J. and Corsini, A., Comparative Investigation on Axial Flow Industrial Fans of High Specific Performance with Unswept and Forward Swept Blades at Design and Off-Design Conditions, Proc. 9th International Symposium Transport Phenomena Dynamics Rotating Machinery, Honolulu, Hawaii, USA, Log. No.FDABS-016, CD-ROM, (2002).

(2) Marcinowski, H., Der Einfluss des Laufradspaltes bei Leitrad Losen, frei Ausblasenden Axialventilator, Voith Forschung und Konstruktion, No.3 (1958).

( 3 ) Wright, T. and Simmons, W.E., Blade Sweep for LowSpeed Axial Fans, ASME J. Turbomachinery, Vol.112 (1991), pp.151-158.

( 4 ) Carolus, T., Ventilatoren, (2003), Teubner Verlag.

( 5 ) Daly, B.B., Fan Noise Measurement I - II. Heating Air Cond. Vent. Inst. (London), No.12, p.414 (1962), No.1, p.14 (1963).

(6) Sanger, N.L. and Shreeve, R.P., Comparison of the Calculated and Experimental Cascade Performance for Controlled-Diffusion Compressor Stator Blading, ASME J. Turbomachinery, Vol.108 (1986), pp.42-50.
( 7 ) HELIOS Hauptkatalog 2001/2002. Druckschrift-Nr. 95 178.005 / 03.01

( 8 ) Videler, J.J., Avian Flight, (2005), Oxford University Press.

( 9 ) Cramp, S. and Brooks, D.J., Handbook of the Birds of Europe, the Middle East and North Africa, (1992), Oxford University Press.

(10) Csörgő, T., Private communication, (2005).

(11) Patterson, G.N., Ducted Fans: Design for High Efficiency, Australian Council for Aeronautics, Rep. ACA 7, (1944).

(12) Corsini, A. and Rispoli, F., The Role of Forward Sweep in Subsonic Axial Fan Rotor Aerodynamics at Design and off-Design Operating Conditions, ASME Paper GT2003-38671, (2003).

(13) Vad, J., Effects of Sweep and Spanwise Changing Circulation Applied to Airfoils: A Case Study, J. Computational and Applied Mechanics, Vol.5, No.2 (2004), pp.383-400.

(14) Vad, J., Kwedikha, A.R.A. and Jaberg, H., Influence of Blade Sweep on the Energetic Behavior of Axial Flow Turbomachinery Rotors at Design Flow Rate, ASME Paper GT2004-53544, (2004).

(15) VDI 3738 Part 12, Environmental Meteorology, Physical Modeling of Flow and Dispersion Processes in the Atmospheric Boundary Layer, Application of Wind Tunnels, (2000).

(16) Goricsán, I., Balczó, M., Régert, T. and Suda, J.M., Comparison of Wind Tunnel Measurement and $\mathrm{Nu}-$ merical Simulation of Dispersion of Pollutants in Urban Environment, Impact of Wind and Storm on City Life and Built Environment, Edited by van Beeck, J.P.A.J., COST C14 International Conference on Urban Wind Engineering and Buildings Aerodynamics, (2004), pp.D.6.1-D.6.10.

(17) Lohász, M.M., Rambaud, P. and Benocci, C., Flow Features in a Fully Developed Ribbed Duct Flow as a Result of LES, ERCOFTAC International Symposium on Engineering Turbulence Modeling and Measurements (ETMM6), Sardinia, Italy, (2005), pp.267276. 